Article

\title{
Investigations of Accessibility of T2/T3 Copper Center of Two-Domain Laccase from Streptomyces griseoflavus Ac-993
}

\author{
Azat Gabdulkhakov ${ }^{1}\left(\mathbb{D}\right.$, Ilya Kolyadenko ${ }^{1}$, Olga Kostareva ${ }^{1}\left(\mathbb{D}\right.$, Alisa Mikhaylina ${ }^{1}$, \\ Paulo Oliveira ${ }^{2,3}$ (), Paula Tamagnini ${ }^{2,3,4}$, Alexander Lisov ${ }^{5}$ and Svetlana Tishchenko ${ }^{1, *}$ \\ 1 Institute of Protein Research RAS, Institutskaya 4, Pushchino, Moscow 142290, Russia \\ 2 i3S-Instituto de Investigação e Inovação em Saúde, Universidade do Porto, 4200-135 Porto, Portugal \\ 3 IBMC - Instituto de Biologia Molecular e Celular, Universidade do Porto, 4200-135 Porto, Portugal \\ 4 Departamento de Biologia, Faculdade de Ciências da Universidade do Porto, 4169-007 Porto, Portugal \\ 5 G.K. Skryabin Institute of Biochemistry and Physiology of Microorganisms, Russian Academy of Sciences, \\ Pushchino 142292, Moscow Region, Russia \\ * Correspondence: sveta@vega.protres.ru
}

Received: 30 May 2019; Accepted: 26 June 2019; Published: 28 June 2019

check for updates

\begin{abstract}
Laccases (EC 1.10.3.2) are multicopper oxidoreductases acting on diphenols and related substances. Laccases are highly important for biotechnology and environmental remediation. These enzymes contain mononuclear one T2 copper ion and two T3 copper ions $\left(\mathrm{Cu} 3_{\alpha}\right.$ and $\left.\mathrm{Cu} 3_{\beta}\right)$, which form the so-called trinuclear center (TNC). Along with the typical three-domain laccases Bacteria produce two-domain (2D) enzymes, which are active at neutral and basic $\mathrm{pH}$, thermostable, and resistant to inhibitors. In this work we present the comparative analysis of crystal structures and catalytic properties of recombinant 2D laccase from Streptomyces griseoflavus Ac-993 (SgfSL) and its four mutant forms with replacements of two amino acid residues, located at the narrowing of the presumable T3-solvent tunnels. We obtained inactive enzymes with substitutions of His165, with Phe, and Ile170 with Ala or Phe. His165Ala variant was more active than the wild type. We suggest that His165 is a "gateway" at the $\mathrm{O}_{2}$-tunnel leading from solvent to the $\mathrm{Cu}_{\beta}$ of the enzyme. The side chain of Ile170 could be indirectly involved in the coordination of copper ions at the T3 center by maintaining the position of the imidazole ring of His157 that belongs to the first coordination sphere of $\mathrm{Cu} 3_{\alpha}$.
\end{abstract}

Keywords: two-domain laccases; crystal structures; T2/T3 copper site; tunnels

\section{Introduction}

Laccases (benzenediol:oxygen oxidoreductases) are copper-containing enzymes that catalyze the oxidation of diverse compounds by molecular oxygen. They are involved in biological processes, such as lignification of plant cell walls and lignin degradation, heavy metal homeostasis and spore morphology. During oxidation by laccases, oxygen is reduced to water, through the transfer of four electrons. The enzyme is used for the transformation of xenobiotics, delignification, and the oxidation of substances of industrial interest (e.g., textile dyes), as well as in cosmetics and medicine [1].

The active center of laccases contains four copper ions: A blue (Cu1) mononuclear copper center (T1) and a trinuclear copper cluster (T2/T3); the latter consists of the mononuclear T2 copper ion (Cu2) and two T3 copper ions $\left(\mathrm{Cu}_{\alpha}\right.$ and $\left.\mathrm{Cu}_{\beta}\right)$ [2]. T1 acts as a center for the reception of electrons from the reducing substrate, while the TNC serves as a binding site for the molecular oxygen and its reduction to water [3]. 
Three-domain (3D) laccases are monomers consisting of three cupredoxin-type domains [4]. two-domain (2D) laccases consist of two domains and exist as homotrimer, with the T2/T3 located at the interface of domain 2 and domain 1 of neighboring molecules, and T1 located near the surface of domain 2 [5].

The TNC plays an important role in functioning of laccases. There are indications that the T1 center is not absolutely required for the activity [6]. The authors have shown that the deletion of domain 3, which contains the T1 copper center from a bacterial 3D laccase does not abolish the activity of the enzyme. The catalytic cycle of 3D and 2D laccases is initiated by the oxidation of a substrate near the $\mathrm{T} 1$ center, four electrons produced by the oxidation of four molecules of substrate are sequentially transferred from the $\mathrm{Cu} 1$ to the TNC, where an oxygen molecule is reduced to water to complete the cycle. The presumed role of $\mathrm{Cu} 2$ and $\mathrm{Cu} 3$ ions is to anchor the dioxygen molecule to the TNC and transient binding of the $\mathrm{OH}^{-}$groups before the addition of a proton and release of water into the outlet tunnel [7].

As TNC is located inside the protein, laccases must contain tunnels providing access of molecular oxygen to the T2/T3 and removal of water. We determined three-dimensional structures of recombinant 2D laccases from Streptomyces viridochromogenes Ac-629 [8] and S. griseoflavus Ac-993 (SgfSL) [9]. Comparative structural analysis of TNC environments of 3D laccases and 2D laccases showed differences in substrate/product transport network, connecting T2/T3 center with surface of the protein [10]. In 3D laccases wide, clearly defined tunnels between the surface and the trinuclear site provide access to the center during the catalytic cycle. While, 2D laccases tunnel(s) are not clearly defined.

In this study, SgfSL has been used as a model system to determine the transport tunnels connecting the TNC with surface. Based on our results, we propose that mobile positively charged side chain of histidine 165 acts as a "gate" in the tunnel that transports oxygen molecules to T2/T3 center.

\section{Results}

\subsection{Structural Comparison of Tunnels of Three-Domain and Two-Domain Laccases}

The structural analysis indicates that the trinuclear cluster [11] and tunnels leading toward the TNC, in 2D and 3D laccases, are different. In structures of 2D laccases copper ions of the T3 center are coordinated by six $\mathrm{N} \varepsilon$ atoms of histidine residues and not by five $\mathrm{N} \varepsilon$ and one $\mathrm{N} \delta$ (like in 3D laccases). Furthermore, tunnel oriented toward the T2 center in 2DLac has a tyrosine residue-a donor of electrons [11]. In the $3 \mathrm{D}$ laccases, the structural position of the $\mathrm{OH}^{-}$group of this residue is occupied by a water molecule. The 3D laccases have two well-defined tunnels approaching the TNC and freely accessible to solvent. As an example, we used the structure of 3D laccase from Steccherinum murashkinskyi with currently the highest resolution for 3D laccases - 0.95 (PDB ID 5E9N). The tunnel leading towards the Cu2 (T2 tunnel) can be responsible for the transport of protons to the active center [12]. The role of the tunnel leading towards the T3 center (T3 tunnel) is probably the transport of molecular oxygen [13,14]. The minimum radius of T3 tunnel of 3DLac S. murashkinskyi is sufficient for passing of oxygen molecules $(1.38 \pm 0.01 \AA)$. The T2 tunnel is rather narrower (the minimum radius is $1.13 \pm 0.01 \AA$ ).

The physical properties of xenon and krypton make them particularly good analogs of dioxygen because of their solubility in hydrophobic environments, and their van der Waals radii are comparable to that of $\mathrm{O}_{2}$. Xenon and/or krypton were used similarly to identify hydrophobic cavities and possible tunnels for oxygen transport in different proteins [15-18].

To find the possible pathways for dioxygen transfer to TNC experimentally, we determined the structures of SgfSL wt derivatized with xenon or krypton. Crystals of SgfSL wt, complexed with xenon or krypton, were obtained using both techniques of Xenon Chamber (Hampton Research) and "soak-and-freeze" methodology at 150 bar pressure [19]. Unfortunately, xenon and krypton-binding sites were only observed within the hydrophobic core of the molecule, and none in the vicinity of TNC. 
The structural analysis shows that the T2/T3 center in 2D laccases are less accessible. In these structures, the chains of water molecules are interrupted by side chains of amino acid residues, which apparently can play the role of a "gateway". Using program Caver [20], we calculated one T3 tunnel (we referred to it as $\mathrm{T} 3_{\alpha}$ ) closely approaching the TNC. The side chain of Ile170 significantly narrowed this tunnel. The second tunnel $\left(\mathrm{T}_{\beta}\right)$ emerged upon rotation on the side chain of His165, which closed the shortest route from the protein surface to the cavity between $\mathrm{Cu} 3_{\alpha}$ and $\mathrm{Cu} 3_{\beta}$ (Figure 1). Taking into account the thermal shaking calculations showed that these tunnels are potentially suitable for the passage of dioxygen.

The existence of a tunnel leading through the central cavity to this histidine was assumed earlier for the laccase of S. coelicolor [5]. In all the available structures of 2D laccases, the histidine is observed in a "closed" conformation and width of the proposed tunnel is $0.71 \pm 0.09 \AA$. We performed a modeling of the sterically resolved state of the side chain of His165 with the hydrogen bonding between the histidine and Asp296 of the neighboring monomer. The resulting displacement widens the tunnel to $1.28 \AA$, which is sufficient for passing of dioxygen. We suggest that "open" and "closed" states of the proposed $\mathrm{T}_{\beta}$ tunnel are provided by the mobility of the imidazole ring His 165 .

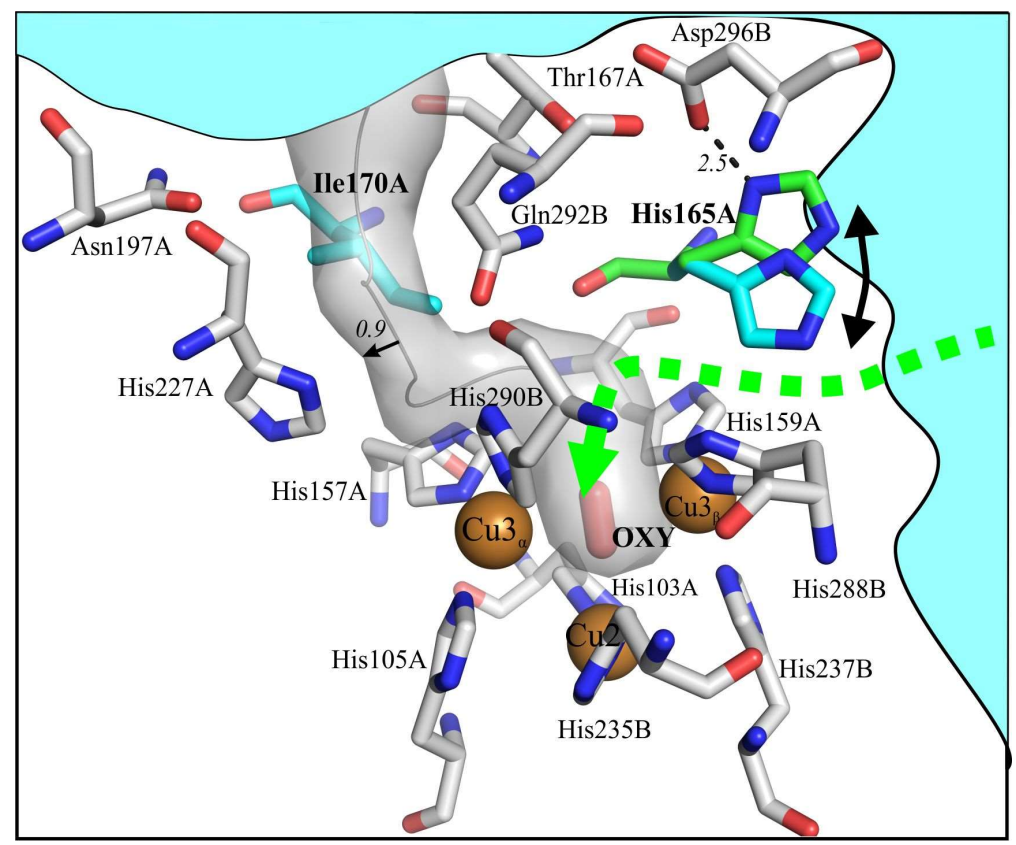

Figure 1. Estimated oxygen tunnels in the SgflSL WT (PDB entry 5LHL). The calculated trajectory of the $\mathrm{T} 3_{\alpha}$ tunnel behind Ile170 is shown in gray. The trajectory of the $\mathrm{T} 3_{\beta}$ tunnel, for which His165 serves as the "gateway", is green. The side chains of His165 is blue in the structure ("close" state) and green in possible open position. OXY - dioxigen. The distances are shown in angstroms. Bulk solvent is shown in cyan. Chains $\mathrm{A}$ and $\mathrm{B}$ belong to the neighboring monomer.

\subsection{SgfSL and Mutants: Crystal Structures and Catalytic Activity}

To assess the accessibility of TNC, we constructed and purified mutant variants of SgfSL by replacing the amino acids, His165 or Ile170, to either Phe or Ala.

We determined the crystal structures of the four mutants and compared them with the structure of the wild type protein. The most important structural parameters are summarized in Table 1, the ligands bound to the TNC, presented in Table S1, and the examples of electron density maps shown in Figure S1. The structures of the mutants confirm the desired single amino acid replacements; no significant changes in the overall fold of the alpha-carbon chain of the enzyme or in the vicinity of the active sites were observed. The r.m.s.d. parameters have never exceeded $0.4 \AA$ A. Significant changes occurred only in the areas of point mutations. In the case of substitutions for phenylalanine (H165F and I170F), 
the tunnels were closed (Figure $2 \mathrm{c}, \mathrm{d}$ ). When replacing isoleucine by alanine at position 170 , the $\mathrm{T} 3 \alpha$ tunnel was expanded to $1.16 \pm 0.11 \AA$ (Figure $2 \mathrm{a}$ ), the H165A mutation expanded the $\mathrm{T} 3_{\beta}$ tunnel even more, to $1.36 \pm 0.14 \AA$ (Figure $2 b$ ), taking into account the estimated maximum coordinate error calculated by SFCHECK [21], which is sufficient for penetration of dioxygen.

Table 1. Crystallographic Data Collection and Refinement Statistics.

\begin{tabular}{|c|c|c|c|c|c|c|}
\hline & $\mathrm{H}_{165 F_{\text {low }} \mathrm{Cu}}$ & H165F & H165A & I170F & I170A & SgfSLwt $_{\text {low }} \mathrm{Cu}$ \\
\hline \multicolumn{7}{|c|}{ Data collection } \\
\hline $\begin{array}{c}\text { Space group } \\
\text { Cell parameters }\end{array}$ & $\mathrm{P} 2{ }_{1}$ & P1 & P1 & P1 & $\mathrm{P} 22_{1}$ & $\mathrm{P} 2_{1}$ \\
\hline a, b, c ( $\mathrm{A})$ & $\begin{array}{c}75.88,95.07 \\
116.82\end{array}$ & $\begin{array}{c}77.03,94.58 \\
115.93\end{array}$ & $\begin{array}{c}77.36,95.12 \\
116.48\end{array}$ & $\begin{array}{c}77.25,94.77 \\
116.18\end{array}$ & $\begin{array}{c}74.79,94.69 \\
116.49\end{array}$ & $\begin{array}{c}75.53,94.62 \\
116.50\end{array}$ \\
\hline$\alpha, \beta, \gamma\left({ }^{\circ}\right)$ & $\begin{array}{c}90.00,90.58 \\
90.00\end{array}$ & $\begin{array}{c}90.00,90.00 \\
92.01\end{array}$ & $\begin{array}{c}90.13,90.11 \\
91.85\end{array}$ & $\begin{array}{c}90.13,89.95 \\
92.56\end{array}$ & $\begin{array}{c}90.00,90.87 \\
90.00\end{array}$ & $\begin{array}{l}90.00,90.39 \\
90.00\end{array}$ \\
\hline $\begin{array}{l}\text { Monomers in } \\
\text { asymmetric unit }\end{array}$ & 6 & 12 & 12 & 12 & 6 & 6 \\
\hline Resolution (Å) & $\begin{array}{c}50.0-2.0 \\
(2.12-2.0)^{\text {a }}\end{array}$ & $\begin{array}{c}50.0-1.92 \\
(2.05-1.92)^{\mathrm{a}}\end{array}$ & $\begin{array}{c}50.0-2.3 \\
(2.45-2.30)^{\mathrm{a}}\end{array}$ & $\begin{array}{c}50.0-1.85 \\
(1.90-1.85)^{\mathrm{a}}\end{array}$ & $\begin{array}{c}50.0-1.98 \\
(2.03-1.98)^{a}\end{array}$ & $\begin{array}{c}50.0-1.80 \\
(1.84-1.80)^{\mathrm{a}}\end{array}$ \\
\hline $\begin{array}{l}\text { Total No. of } \\
\text { reflections }\end{array}$ & $\begin{array}{l}206,927 \\
(29,456)\end{array}$ & $\begin{array}{c}833,269 \\
(147,319)\end{array}$ & $\begin{array}{l}507,815 \\
(80,770)\end{array}$ & $\begin{array}{l}536,185 \\
(26,532)\end{array}$ & $\begin{array}{l}757,980 \\
(54,090)\end{array}$ & $574,463(45,966)$ \\
\hline $\begin{array}{l}\text { No. of unique } \\
\text { reflections }\end{array}$ & $\begin{array}{c}90,309 \\
(14,288)\end{array}$ & $\begin{array}{l}235,591 \\
(80,443)\end{array}$ & $\begin{array}{l}143,173 \\
(22,664)\end{array}$ & $\begin{array}{l}256,815 \\
(12,984)\end{array}$ & $\begin{array}{c}112,783 \\
(8272)\end{array}$ & $151,965(11,814)$ \\
\hline Rmerge (\%) & $10.5(50.8)$ & $9.1(86.0)$ & $11.0(83.8)$ & $8.2(88.7)$ & $12.5(87.5)$ & $6.6(88.2)$ \\
\hline $\mathrm{I} / \sigma(\mathrm{I})$ & $5.41(1.49)$ & $7.88(1.57)$ & $9.35(1.42)$ & $5.89(0.96)$ & $10.13(2.30)$ & $9.86(1.55)$ \\
\hline Completeness (\%) & $80.2(78.9)$ & $94.3(92.9)$ & $98.0(95.9)$ & $91.4(62.2)$ & $99.8(99.9)$ & $99.4(99.7)$ \\
\hline $\mathrm{CC}_{1 / 2}$ & $0.99(0.69)$ & $0.99(0.63)$ & $0.99(0.57)$ & $0.99(0.35)$ & $0.99(0.73)$ & $0.99(0.67)$ \\
\hline Redundancy & $2.29(2.06)$ & $3.59(3.55)$ & $3.55(3.57)$ & $2.09(2.04)$ & $6.72(6.54)$ & $3.78(3.89)$ \\
\hline \multicolumn{7}{|c|}{ Refinement } \\
\hline Resolution $(\AA ̊)$ & $\begin{array}{l}49.77-2.00 \\
(2.02-2.00)\end{array}$ & $\begin{array}{l}49.41-1.95 \\
(1.98-1.95)\end{array}$ & $\begin{array}{c}49.7-2.3 \\
(2.34-2.31)\end{array}$ & $\begin{array}{l}47.33-1.85 \\
(1.87-1.85)\end{array}$ & $\begin{array}{l}49.60-1.98 \\
(2.01-1.98)\end{array}$ & $\begin{array}{l}45.97-1.80 \\
(1.84-1.80)\end{array}$ \\
\hline No. reflections & 90,303 (5785) & $\begin{array}{l}225,948 \\
(20,608)\end{array}$ & $\begin{array}{c}143,173 \\
(6693)\end{array}$ & $\begin{array}{c}256,747 \\
(5256)\end{array}$ & $\begin{array}{l}112,768 \\
(3514)\end{array}$ & $150,800(10,599)$ \\
\hline Rwork (\%) & $19.97(31.94)$ & $19.47(30.86)$ & $17.09(26.66)$ & $17.85(35.78)$ & $17.40(24.36)$ & $14.20(27.78)$ \\
\hline$R_{\text {free }}(\%)$ & $23.32(35.91)$ & $23.10(32.81)$ & $22.21(30.83)$ & $23.70(39.29)$ & $21.48(29.57)$ & $17.94(32.88)$ \\
\hline \multicolumn{7}{|l|}{ R.m.s. deviations } \\
\hline Bond lengths $(\AA)$ & 0.008 & 0.008 & 0.008 & 0.008 & 0.007 & 0.007 \\
\hline Bond angles $\left({ }^{\circ}\right)$ & 0.928 & 0.995 & 0.961 & 0.874 & 0.854 & 0.823 \\
\hline \multicolumn{7}{|l|}{$\begin{array}{l}\text { Ramachandran } \\
\text { plot (\%) }\end{array}$} \\
\hline Most favored & 96.91 & 96.78 & 94.66 & 96.40 & 98.07 & 97.82 \\
\hline $\begin{array}{l}\text { Additionally } \\
\text { allowed }\end{array}$ & 3.09 & 3.07 & 4.88 & 3.60 & 1.93 & 2.18 \\
\hline $\begin{array}{l}\text { Generously } \\
\text { allowed }\end{array}$ & 0.00 & 0.15 & 0.46 & 0.00 & 0.00 & 0.00 \\
\hline PDB ID & $5 \mathrm{MKM}$ & $6 \mathrm{FC7}$ & 6FDJ & 6RH9 & $6 \mathrm{RHQ}$ & $6 \mathrm{~S} 0 \mathrm{O}$ \\
\hline
\end{tabular}




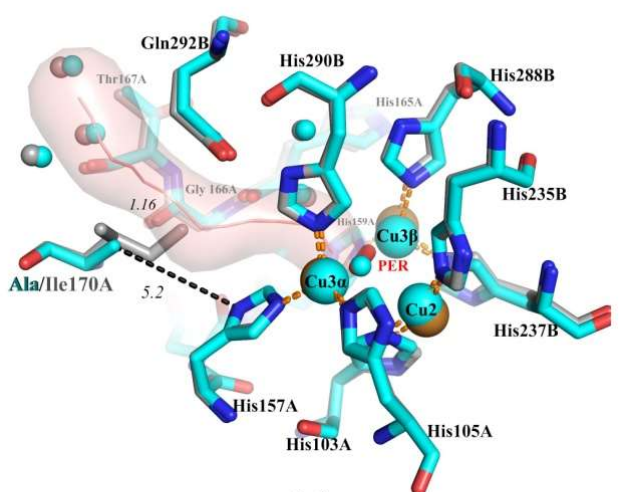

(a)

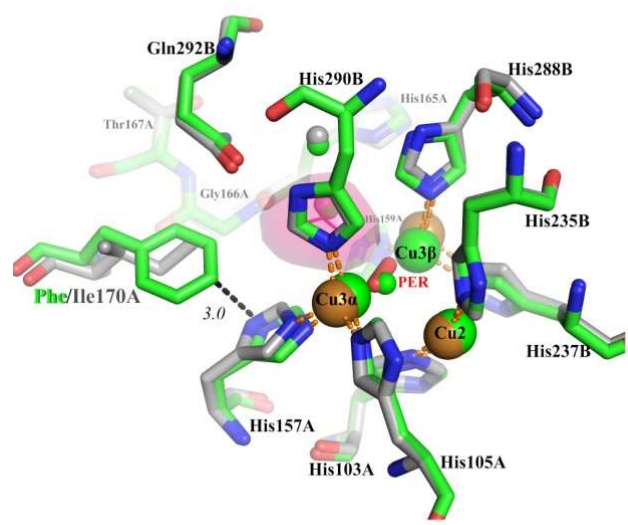

(c)

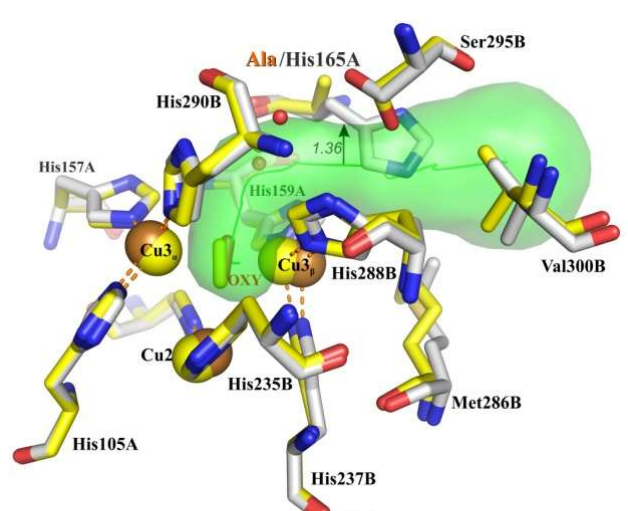

(b)

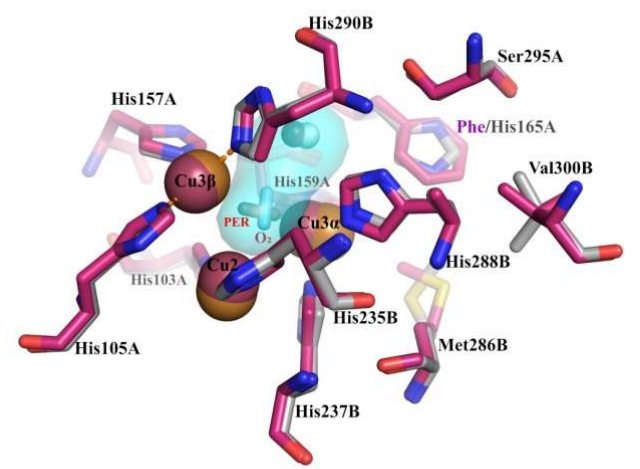

(d)

Figure 2. Structure of the T2/T3 center of SgfSL Ile170Ala variant (a), His165Ala (b), Ile170Phe (c) and His165Phe (d). PER - peroxide ion, OXY - dioxigen. Copper ions are shown as spheres. The distances between atoms are in angstroms. Residues of the wild type protein are shown in gray, residues of mutant proteins are shown in various colors. The trajectories of tunnels are shown as colored semi-transparent shapes.

As the substitutions introduced to the SgfSL did not change the fold of alpha-carbon chain in the active site, we reasoned that possible differences in activity must be attributed solely to the mutations themselves.

The structures of SgfSL, and its mutant forms with sufficient occupancy of copper ions, were obtained via the cultivation of the corresponding over-producer, the E. coli strain, in a medium with a high concentration of copper(II) sulfate $(1 \mathrm{mM})$; in the case of cultivation with $0.25 \mathrm{mM} \mathrm{CuSO}_{4}$, the laccase crystal structures were deprived of copper (Table 2) [10].

Table 2. Occupancy and B-factor of copper ions.

\begin{tabular}{|c|c|c|c|c|c|c|c|c|}
\hline \multirow[t]{2}{*}{ Protein } & \multicolumn{2}{|c|}{ Cu1 } & \multicolumn{2}{|c|}{$\mathrm{Cu}_{\alpha}$} & \multicolumn{2}{|c|}{$\mathrm{Cu}_{\beta}$} & \multicolumn{2}{|c|}{$\mathrm{Cu} 2$} \\
\hline & $\begin{array}{c}\text { Occupancy * } \\
(\%)\end{array}$ & $\begin{array}{c}\text { B-factor * } \\
\left(\AA^{2}\right)\end{array}$ & $\begin{array}{c}\text { Occupancy * } \\
(\%)\end{array}$ & $\begin{array}{c}\text { B-factor * } \\
\left(\AA^{2}\right)\end{array}$ & $\begin{array}{c}\text { Occupancy* } \\
(\%)\end{array}$ & $\begin{array}{c}\text { B-factor * } \\
\left(\AA^{2}\right)\end{array}$ & $\begin{array}{c}\text { Occupancy * } \\
(\%)\end{array}$ & $\begin{array}{c}\text { B-factor * } \\
\left(\AA^{2}\right)\end{array}$ \\
\hline SgfSLwt & 0.98 & 19 & 1.00 & 21 & 1.00 & 24 & 0.48 & 56 \\
\hline SgfSLwt $_{\text {low }} \mathrm{Cu}$ & 1.00 & 31 & 1.00 & 39 & 0.88 & 48 & 0.22 & 73 \\
\hline $\mathrm{H}_{165 \mathrm{~F}_{\text {low } \mathrm{Cu}}}$ & 1.00 & 22 & 0.92 & 28 & 0 & 0 & 0 & 0 \\
\hline $\mathrm{H} 165 \mathrm{~F}$ & 0.96 & 27 & 0.96 & 34 & 0.70 & 38 & 0.27 & 40 \\
\hline H165A & 0.98 & 28 & 0.99 & 35 & 0.95 & 40 & 0.48 & 40 \\
\hline I170F & 1 & 31 & 1 & 35 & 0.97 & 39 & 0.53 & 100 \\
\hline I170A & 1 & 25 & 0.97 & 31 & 0.75 & 38 & 0.19 & 50 \\
\hline
\end{tabular}


Tables 1-3 represent the data related to the SgfSL mutants that were expressed in a medium

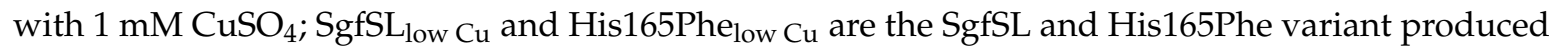
in a medium supplemented with $0.25 \mathrm{mM} \mathrm{CuSO}_{4}$. In the case of low concentration of $\mathrm{CuSO}_{4}$, the structure of the mutant protein lacks not only copper $\mathrm{Cu} 2$, but also $\mathrm{Cu} 3_{\beta}$.

We used ABTS and $\mathrm{K}_{4}\left[\mathrm{Fe}(\mathrm{CN})_{6}\right]$ as electron donors and phenolic compound 2,6-DMP as combined electron and proton donor. The laccase oxidized ABTS and $\mathrm{K}_{4}\left[\mathrm{Fe}(\mathrm{CN})_{6}\right]$ at $\mathrm{pH} 4.0,2,6-\mathrm{DMP}$ was oxidized at $\mathrm{pH}$ 9.0. Substrate affinity $\left(\mathrm{K}_{\mathrm{m}}\right)$, turnover rates $\left(\mathrm{k}_{\mathrm{cat}}\right)$ and catalytic efficiency $\left(\mathrm{k}_{\mathrm{cat}} / \mathrm{K}_{\mathrm{m}}\right)$ values for each enzyme are listed in Table 3 and Figure S2. The specific activity of SgfSL toward phenolic compound was lower than toward electron donors, $\mathrm{ABTS}$ and $\mathrm{K}_{4}\left[\mathrm{Fe}(\mathrm{CN})_{6}\right]$.

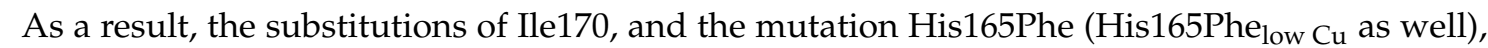
dramatically affected the activity of the SgfSL. These mutants showed significantly reduced turnover number for $\mathrm{ABTS}, \mathrm{K}_{4}\left[\mathrm{Fe}(\mathrm{CN})_{6}\right]$; and these variants were incapable of oxidizing 2,6-DMP. The catalytic efficiency of His165Ala variant was slightly higher than that of the SgfSL wt (Table 3).

Table 3. Kinetic parameters of the SgfSL variants.

\begin{tabular}{|c|c|c|c|c|c|}
\hline Substrate & Protein & $\begin{array}{c}\mathrm{K}_{\mathrm{m}} \\
(\mathrm{mM})\end{array}$ & $\begin{array}{l}\mathrm{k}_{\mathrm{cat}} \\
\left(\mathrm{s}^{-1}\right)\end{array}$ & $\begin{array}{c}\mathrm{k}_{\mathrm{cat}} / \mathrm{K}_{\mathrm{m}} \\
\left(\mathrm{mM}^{-1} \mathrm{~s}^{-1}\right)\end{array}$ & Activity $\mathrm{nM} \mathrm{O}_{2} \min ^{-1} \mu \mathrm{g}^{-1}$ \\
\hline \multirow[t]{6}{*}{ ABTS } & SgfSL WT & $0.10 \pm 0.008$ & $6.60 \pm 0.12$ & 66.28 & $0.82 \pm 0.01$ \\
\hline & H165A & $0.12 \pm 0.01$ & $10.80 \pm 0.21$ & 90.00 & $1.45 \pm 0.10$ \\
\hline & $\mathrm{H} 165 \mathrm{~F}$ & $0.45 \pm 0.03$ & $0.12 \pm 0.009$ & 0.26 & $0.13 \pm 0.06$ \\
\hline & $\mathrm{H} 165 \mathrm{~F}_{\text {low } \mathrm{Cu}}$ & $0.47 \pm 0.02$ & $0.11 \pm 0.007$ & 0.23 & $0.10 \pm 0.03$ \\
\hline & I170A & $0.63 \pm 0.11$ & $0.70 \pm 0.20$ & 1.11 & $0.11 \pm 0.01$ \\
\hline & $\mathrm{I} 170 \mathrm{~F}$ & $0.20 \pm 0.04$ & $0.08 \pm 0.01$ & 0.40 & $0.08 \pm 0.04$ \\
\hline \multirow[t]{6}{*}{ 2,6-DMP } & SgfSL WT & $5.20 \pm 0.11$ & $0.80 \pm 0.09$ & 0.15 & \\
\hline & H165A & $6.10 \pm 0.34$ & $1.10 \pm 0.06$ & 0.18 & \\
\hline & $\mathrm{H} 165 \mathrm{~F}$ & - & - & - & \\
\hline & $\mathrm{H} 165 \mathrm{~F}_{\text {low }} \mathrm{Cu}$ & - & - & - & \\
\hline & I170A & - & - & - & \\
\hline & I170F & - & - & - & \\
\hline \multirow[t]{5}{*}{$\mathrm{K}_{4}\left[\mathrm{Fe}(\mathrm{CN})_{6}\right]$} & SgfSL WT & & & & $2.28 \pm 0.17$ \\
\hline & H165A & & & & $6.47 \pm 0.27$ \\
\hline & $\mathrm{H} 165 \mathrm{~F}$ & & & & $0.26 \pm 0.12$ \\
\hline & $\mathrm{I} 170 \mathrm{~A}$ & & & & $0.18 \pm 0.01$ \\
\hline & I170F & & & & $0.14 \pm 0.04$ \\
\hline
\end{tabular}

- no activity.

Laccases are strongly inhibited by azide ions. The activity of 3D laccases was completely abolished by low concentrations of sodium azide (ranging from several $\mu \mathrm{M}$ to $1-2 \mathrm{mM}$ ) [22,23]. High resistance to inhibition by sodium azide was observed in 2D laccases previously [5]. We examined the effect of sodium azide on the activity of wild type SgfSL and its mutants. The inhibition assays were carried out at $\mathrm{pH} 4.0$, using ABTS as a substrate. In the presence of $10 \mathrm{mM} \mathrm{NaN}_{3}$ activity of wild type SgfSL was decreased to $53.9 \%$, whereas the activity of the His165Ala variant was increased by thirty percent.

The thermostability of His165Ala variant is as high as that of wild type SgfSL; it retained approximately $80 \%$ of its initial activity after the $40 \mathrm{~min}$ incubation at $80^{\circ} \mathrm{C}$.

\section{Discussion}

\subsection{Ile170 Could Be Indirectly Involved in The Coordination of $\mathrm{Cu}_{\alpha}$ Ion within the TNC}

We extensively studied the routes leading to the TNC of 2D laccase SgfSl. The inability to identify tunnels using the noble gases forced us to use point mutations in SgfSL. We assumed that there are two routes leading to TNC of 2DLac, which were potentially suitable for the passage of dioxygen or water and probably copper ions. 
One of the proposed T3 tunnels is blocked by the Ile170. Replacing Ile170 to alanine and phenylalanine result in a strong decrease in catalytic activity by an order of magnitude (Table 3). The expansion of the proposed $\mathrm{T} 3 \alpha$ tunnel upon replacing isoleucine to alanine (Figure 2a) did not increase enzymatic activity. Apparently, the role of Ile170 is not related to modulating dioxygen access to the TNC through this tunnel. We assumed that Ile170 is rather indirectly involved in the coordination of $\mathrm{Cu} 3_{\alpha}$ ion within the TNC. Indeed, the detailed comparative analysis of the structures of the wild type SgfSL and its two mutant forms showed that Ile170 can affect (via hydrophobic interactions) the position and mobility of the His157, belonging to the 1st coordination sphere of the $\mathrm{Cu} 3 \alpha$.

It was observed that the $\mathrm{Cu} 3_{\alpha}-\mathrm{Cu} 3_{\beta}$ distance in the TNC is highly variable [24], which is important for stabilizing coordination geometries and mediating proton transfer reactions $[25,26]$ The change in the distance is observed when going from the oxidized to partially and fully reduced structures. In the reduced structure these distances are the shortest and decreased by approximately $1 \AA$ [27].

In our laccase structures, the $\mathrm{Cu}_{\alpha}-\mathrm{Cu} 3_{\beta}$ distance in the TNC varied by more than $1 \AA$, from $3.96 \pm 0.10 \pm 0.11 \AA$ in the Ile170Phe to $5.24 \pm 0.04 \pm 0.08 \AA$ in the wild type (the average value for monomers in an asymmetric unit with standard deviation and estimated maximum coordinate error). Therefore, Ile170 indirectly affects the location of theCu3 $3_{\alpha}$. In case of Ile170Ala substitution, Ala is unable to establish nonpolar interactions through its side chain and hence it does not interact with His157, which may cause excessive mobility of imidazole ring of His157. In case of the Ile170Phe replacement, the imidazole ring of His157 can be more strongly fixed (Figure 2c) than it is required for the enzyme functioning. Both replacements of Ile170, inhibit the reduction of oxygen to water, within the TNC and catalytic activity of SgfSL is decreased.

Thus, the structure-function relationship was established for the second coordination sphere residue that explains the decreased activity of SgfSL with substitutions of the Ile170.

\subsection{Histidine 165 Is $A$ "Gateway" of T3 Tunnel Leading to $C u 3_{\beta}$ of T2/T3 Center}

The shortest route from the protein surface to the TNC exists in a direction through a structurally conserved His165. This residue is located at the entrance of the proposed dioxygen tunnel. In the majority of 2D laccases structures access through this tunnel was blocked by His165. The same feature was observed in the 3D laccase from Thermus thermophilus (PDB entry 2XU9), opening and closing of the T3 tunnel can be provided by the mobility of the side chains of His137 (structural analog of His165) and Glu451. We considered that the replacement of the His165 ("gateway" of the proposed tunnel) to alanine could fix the tunnel in an open state, and the hydrophobic phenylalanine should close the tunnel (Figure 1).

In line with our hypothesis, His165Phe variant showed drastically reduced turnover rates for ABTS; its catalytic efficiency decreased by a factor of 255 compared to SgfSL wt. Oxygen consumption decreased 6-fold for ABTS and by one order of magnitude for $\mathrm{K}_{4}\left[\mathrm{Fe}(\mathrm{CN})_{6}\right]$; no activity was detected towards 2,6-DMP (Table 3).

His165Phe low $\mathrm{Cu}_{\text {was }}$ obtained from an overproducer strain cultivated with $0.25 \mathrm{mM} \mathrm{CuSO}_{4}$. Interestingly, not only $\mathrm{Cu} 2$ but also $\mathrm{Cu} 3_{\beta}$ were absent from the structure of this mutant (PDB entry $5 \mathrm{MKM}$ ). Recently, we have shown that the $\mathrm{T} 3_{\beta}$ of SgfSL is accessible for copper ions during dialysis of the protein preparation [10]. We propose that shuttering the $\mathrm{T} 3_{\beta}$ tunnel in the His165Phe mutant may impede copper ion access to the TNC. This would explain why saturation of TNC with copper ions could only be reached at the increased $(1 \mathrm{mM})$ copper content in the growth medium (Table 2). The shuttering of the $\mathrm{T} 3_{\beta}$ tunnel likely impedes the access of dioxygen to the TNC, which would be

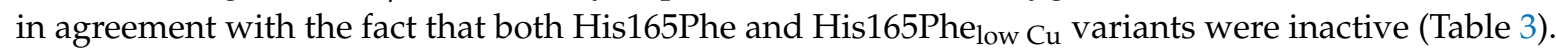
Thus the Phe at the position 165 may hinder the access of both dioxygen and $\mathrm{Cu}$ ions to the TNC via the $\mathrm{T} 3_{\beta}$ tunnel (Figure 2c).

The His165Ala variant possessed a catalytic efficiency slightly higher than that of the wild type SgfSL: Oxygen consumption increased 1.7-fold for ABTS and 2.8-fold for $\mathrm{K}_{4}\left[\mathrm{Fe}(\mathrm{CN})_{6}\right]$ (Table 3). 
This could be explained by the increased oxygen access to the TNC upon the change of His165 to Ala. We assumed that His165 can regulate the oxygen supply via short $\mathrm{T} 3_{\beta}$ tunnel to TNC.

It is known that the different $\mathrm{O}_{2}$-reduction states and intermediates of $3 \mathrm{D}$ laccases could be observed in the crystals with different X-ray-absorbed doses $[14,26]$. In the case of the structure of the His165Ala variant, we noted movement of dioxygen and water molecules within the TNC in molecules of the asymmetric unit (Figure 3). We observed the " $\mathrm{O}_{2}$-state" with symmetrically coordinated $\mathrm{O}_{2}$ amidst the binuclear T3 copper ions in 6 molecules of laccase (Figure 3a), oxidized "resting state" with bridging hydroxid $\left(\mathrm{OH}^{-}\right)$in 4 molecules (Figure $3 \mathrm{~b}$ ) and fully $\mathrm{Cu}$ reduced state without ligands between $\mathrm{T} 3$ copper ions in 2 molecules (not shown).

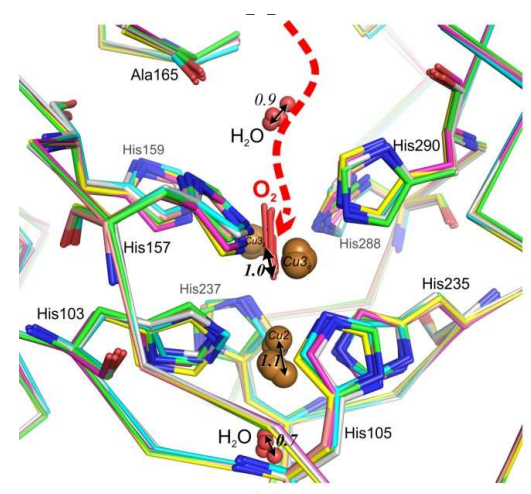

(a)

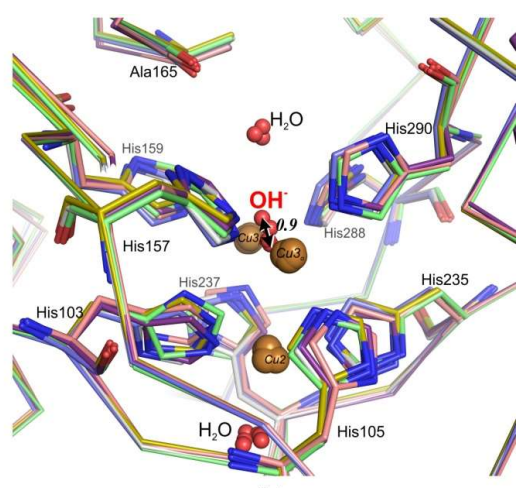

(b)

Figure 3. View of TNC at superposition of the monomers His165Ala of asymmetric unit. (a) " $\mathrm{O}_{2}$ -state", (b) "Resting state". The dotted line shows the $\mathrm{T} 3_{\beta}$ tunnel. The distances between the extreme positions of atoms are shown in angstroms.

Superposition of 12 monomers in the asymmetric unit, using C $\alpha$ atoms gave r.m.s.d. of $0.31 \pm 0.14 \AA$, we obtained the same values for copper ions at the T3 center, indicating a good result at $2.3 \AA$ A resolution. However, positions of $\mathrm{Cu} 2$, water molecules, dioxygen, and hydroxyl ion varied within approximately $1 \AA$, which allowed different stages of dioxygen penetration into the TNC and the hydroxyl release to be observed. (Figure 3).

It was shown recently that $\mathrm{NaN}_{3}$ reduced laccase activity of 2D laccases at acidic conditions, and no inhibition was observed at basic $\mathrm{pH}$ in the presence of up to $100 \mathrm{mM}$ inhibitor [8]. It was observed that, in contrast to the wild type enzyme, the His165Ala variant demonstrates an increased activity under acidic conditions in the presence of $10 \mathrm{mM} \mathrm{NaN}_{3}$. The replacement of a positively charged His (at acidic $\mathrm{pH}$ ) to non-polar Ala at the entrance to the single $\mathrm{T} 3$ tunnel reduces attraction of of the TNC for the negatively charged azide ions. We presently have no reliable explanation for activation of the His165Ala variant with azide at acidic $\mathrm{pH}$. However, we would propose that azide ion can bind to 2D laccases at an alternative site, which could activate the enzyme to some extent. Indeed, we have recently demonstrated that in the structure of another 2D laccase Streptomyces lividans Ac 1709 (PDB ID 4GYB) azide is bound near the T1 center in the vicinity of the substrate-binding pocket. However, the mechanism of this phenomenon requires further research.

In summary, we suggest that the $\mathrm{T} 3_{\beta}$ tunnel of $2 \mathrm{D}$ laccases can provide access of dioxygen, copper ions and inhibitor ions to the TNC. The investigations of accessibility of the TNC of 2D laccases can provide insights into the fundamental process of $\mathrm{O}_{2}$ reduction to $\mathrm{H}_{2} \mathrm{O}$, and also will be important to the development of industrial and biomedical applications. Boosted activity and resistance to inhibitors of the His165Ala variant along with its high thermostability can be useful for industrial application of 2DLac. 


\section{Materials and Methods}

\subsection{Plasmid Construction}

The pQE-30-based plasmid pQE-993nS carrying the gene encoding SgfSL deprived of the N-terminal signal sequence [10] was used as a template for the PCR with a pair of corresponding mutagenic primers (replaced nucleotides are in italic and underlined). Herein and after, the N-terminal truncated SgfSL will be referred to as the wild type (SgfSL wt) as the truncation does not affect the catalytic activity.

His165Ala_For: 5' - TCGGCACGGAAGCGGGCACGGGCGGCAT

His165Ala_Rev: 5' - ATGCCGCCCGTGCCCGCTTCCGTGCCGA

His165Phe_For: 5' - TCGGCACCGAATTTGGCACCGGCGGCATTCGCAACGG

His165Phe_Rev: 5' - GCCGCCCGTGCCAAATTCCGTGCCGACGACGTGGTC

Ile170Ala_For: 5' - GAACACGGCACCGGAGGA GCGCGCAATGGCCTGTATGGA

Ile170Ala_Rev: 5' - CGGTCCATACAGGCCATTGCGCGCTCCTCCGGTGCCGTGTTC

Ile170Phe_For: 5'-CGGCACCGGGGGGTTTCGCAACGGCCTGTACGG

Ile170Phe_Rev: 5' - CCGTACAGGCCGTTGCGAAACCCCCCGGTGCCG

Amplification of target template was carried out by KOD Hot Start DNA Polymerase (Novagen, Germany), according to the manufacturer protocol. Then, the PCR products were digested with DpnI and used for the transformation of Escherichia coli DH5 $\alpha$ competent cells.

As we failed to express SgfSL mutants I170A and I170F, using the obtained pQE-30-based vectors, these mutants were cloned in another expression vector, pET32-Xa_Lic. The genes of I170A and I170F SgfSL mutants were PCR-amplified using the corresponding pQE-30-based plasmids as a template, and the following pair of primers:

For 5' - AGATCTGGGTACCATCGAGGGTCGTGCAGGAGCAGCGCCCGCCGGGGGA -3'

Rev 5' - GGCTGCAAGCTTTCAGTGAGCGTGCTCCTGCGGGT -3'

The PCR products obtained were digested with Hind III and Kpn I (Sibenzyme, Russia) and inserted to the pET32-Xa_Lic vector, treated with the same enzymes.

\subsection{Purification of SgfSL Mutants}

The E. coli strain M15 (pREP4) (Qiagen, Stockach, Germany) was transformed with the pQE-993nS, pQE30/H165A SgfSL or pQE30/H165F SgfSL. The E. coli strain BL21(DE3)/Rosetta (Qiagen, Stockach, Germany) was transformed with pET32/I170A SgfSL or pET32/I170F SgfSL. Cells were grown at $37^{\circ} \mathrm{C}$ with shaking at $150 \mathrm{rev} / \mathrm{min}$ to $\mathrm{OD}_{600}=0.5$. The production of SgfSL variants was induced by addition of isopropyl $\beta$-D-1-thiogalactopyranoside (IPTG) to a final concentration of $0.1 \mathrm{mM}$. Along with IPTG, $\mathrm{CuSO}_{4}$ was added to a final concentration of 0.25 (low copper conditions) or $1 \mathrm{mM}$ (high copper conditions). After induction, the cells were incubated for $18 \mathrm{~h}$ with shaking (50 rev/min) at either $18^{\circ} \mathrm{C}$ (in case of $\mathrm{H} 165 \mathrm{~A}$ and $\mathrm{H} 165 \mathrm{~F}$ mutants) or $30^{\circ} \mathrm{C}$ (in case of I170A SgfSL and I170F mutants).

In each case, cells were collected by centrifugation at $5000 \mathrm{~g}$ for $15 \mathrm{~min}$, suspended in buffer A (20 mM phosphate buffer $\mathrm{pH} 7.4$, containing $0.5 \mathrm{M} \mathrm{NaCl}$ and $20 \mathrm{mM}$ imidazole) with $1 \mathrm{mM}$ phenylmethylsulfonyl fluoride and $200 \mathrm{ng} / \mathrm{mL}$ DNAase I and disrupted using EmulsiFlex-C3 high pressure homogenizer (Avestin, Ottawa, ON, Canada). Cell debris was removed by centrifugation (30 min at 15,000g) and the supernatant was loaded onto a column packed with Ni-NTA Agarose (Qiagen, Stockach, Germany) equilibrated with the buffer A. Then, the column was washed with four column volumes of the buffer A and the protein was eluted with the buffer A containing $150 \mathrm{mM}$ imidazole.

For I170A and I170F mutants, fractions after Ni-NTA Agarose column were collected and dialyzed against a buffer for proteolysis (50 mM Tris- $\mathrm{HCl}, \mathrm{pH} 8.0,100 \mathrm{mM} \mathrm{NaCl})$. Proteolysis was carried out for $16 \mathrm{~h}$ at room temperature by adding $1 \mathrm{U}$ factor Xa protease (SIGMA-ALDRICH, Taufkirchen, Germany) per $1 \mathrm{mg}$ of recombinant protein and $\mathrm{CaCl}_{2}$ to $1 \mathrm{mM}$. Following Ni-affinity chromatography made mutant proteins without thioredoxin N-terminal tail. For crystallization, all preparations of 
SgfSL variants were concentrated to $20-30 \mathrm{mg} / \mathrm{mL}$ and dialyzed against $50 \mathrm{mM} \mathrm{H}_{3} \mathrm{BO}_{3}-\mathrm{NaOH}, \mathrm{pH} 9.0$, $100 \mathrm{mM} \mathrm{NaCl}$.

\subsection{Activity Assays}

The optimum $\mathrm{pH}$ for laccase activity was determined at $30^{\circ} \mathrm{C}$ using a $50 \mathrm{mM}$ Britton-Robinson buffer within the $\mathrm{pH}$ range 2.5-5.5 for 2,2-azino-bis-(3-ethylbenzthiazoline-6-sulfonate)-ABTS and within the $\mathrm{pH}$ range 6-10 for 2,6-dimethoxyphenol-2,6-DMP. The reaction mixture contained $1 \mathrm{mM}$ substrate (ABTS or 2,6-DMP) and the enzyme variant $(0.7-5 \mu \mathrm{g} / \mathrm{mL}$ ). The laccase activity was determined as the amount of ABTS oxidation at $30^{\circ} \mathrm{C}$ for $30 \mathrm{sec}$ at the optimum $\mathrm{pH}$.

Oxygen consumption was monitored at $30^{\circ} \mathrm{C}$ in $50 \mathrm{mM}$ Britton-Robinson buffers with $\mathrm{pH}$ optimum (4.0) with a Clark-type oxygen electrode (Hansatech, Norfolk, UK) for $60 \mathrm{sec}$; the concentrations of the substrate (ABTS or $\mathrm{K}_{4}\left[\mathrm{Fe}(\mathrm{CN})_{6}\right]$ ) and the enzyme variants were $1 \mathrm{mM}$, and $10 \mu \mathrm{g} / \mathrm{mL}$, respectively.

Molar extinction coefficients were used to determine the reaction products were $\varepsilon_{469}=49,600 \mathrm{M}^{-1}$ $\times \mathrm{cm}^{-1}$ for 2,6-DMP and $\varepsilon_{420}=36,000 \mathrm{M}^{-1} \times \mathrm{cm}^{-1}$ for ABTS [28,29]. It was taken into account that the enzyme is a homotrimer. All kinetic experiments were performed in triplicate. The resulting curves were fitted to the Michaelis-Menten equation by non-linear least-square regression with Origin 9.1 (Figure S2). The rate of oxygen consumption was determined using OxyGraph software systems (Hansatech, Norfolk, UK).

To test thermostability, a laccase variant $(1 \mathrm{mg} / \mathrm{mL}$ in the Britton-Robinson buffer at optimal $\mathrm{pH})$ was incubated at $80^{\circ} \mathrm{C}$ for $40 \mathrm{~min}$. After incubation, samples were immediately chilled on ice. Residual activities were calculated taking the initial activity of the enzyme as $100 \%$.

To study the inhibition of laccase variants by sodium azide, the measurements were performed at $30^{\circ} \mathrm{C}$ in $50 \mathrm{mM}$ Britton-Robinson buffer with optimal $\mathrm{pH}, 10 \mathrm{mM} \mathrm{NaN}_{3}$ and enzymes at a concentration of $1 \mu \mathrm{g} / \mathrm{mL}$. The residual activity was calculated taking the initial activity of the enzyme without $\mathrm{NaN}_{3}$ as $100 \%$.

\subsection{Crystallization and Crystallography}

Crystallization experiments were performed at $23^{\circ} \mathrm{C}$ using the hanging-drop vapour-diffusion method on siliconized glass cover slides in Linbro plates (Molecular Dimensions, Suffolk, UK). Drops were made by mixing $2 \mu \mathrm{L}$ of protein at a concentration of $10-20 \mathrm{mg} / \mathrm{mL}$ in $0.1 \mathrm{M} \mathrm{NaCl}, 0.05 \mathrm{M}$ $\mathrm{H}_{3} \mathrm{BO}_{3}-\mathrm{NaOH} \mathrm{pH} 9.0$ and $1 \mu \mathrm{L}$ of reservoir solution.

The reservoir solution consisted of 20\% PEG 6000, 0.1 M Bicine, $\mathrm{pH} 9.0$ for H165A and H165F variants and 25\% Smear medium PEG, 0.1 M Bicine, pH 9.0 (condition \#21 of BCS-2 from Molecular Dimensions, Suffolk, UK) for I170A and I170F variants. For diffraction data collection, a single crystal was flash cooled after soaking in a solution consisting of $25 \%$ PEG 4000, 15\% glycerol, $0.1 \mathrm{M}$ Tris- $\mathrm{HCl}$ $\mathrm{pH} 8.0$ prior to data collection.

Diffraction data for wild type, H165F, H165A, I170F and I170A variants have been collected on the beamline BL14.1 at the BESSY II electron storage ring operated by the Helmholtz-Zentrum Berlin [30] using Pilatus 6M detector [31]. Data for $\mathrm{H}_{165 \mathrm{~F}_{\text {low }} \mathrm{Cu}}$ were collected at the beamline P11 (PETRA III, Hamburg). All data were processed and merged using the XDS package [32]. Crystallographic data statistics are summarized in Table 1.

The structures were determined by molecular replacement with Phaser [33] using the structure of a mutant laccase from S. griseoflavus determined at 1.9 A resolution (PDB entry 5O4Q [10]) as a search model. Water molecules and metal ions were removed from the model. The initial model was subjected to crystallographic refinement with REFMAC5 [34]. Manual rebuilding of the model was carried out in Coot [35]. The final refinement cycle with refinement of occupancy with the copper ions was performed in Phenix [36]. Data and refinement statistics are summarized in Table 1. The atom coordinates and structure factors have been deposited in the Protein Data Bank. Figures were prepared using PyMOL [37]. The tunnels leading from the protein surface to the TNC were calculated using Caver [20]. 


\subsection{Noble Gas Pressurization}

Prior to data collection, the crystals were incubated with xenon at 10,15, and 30 bar, and with krypton at 40 bar, for 2-20 min in a Xenon Chamber (Hampton Research, Aliso Viejo, CA, USA) and after that flash frozen in liquid nitrogen at BESSY. We also used the technique "soak-and-freeze" developed in the ESRF by Carpentier [19], and worked on crystals by krypton at pressures from 142 to 150 Bar.

Supplementary Materials: Supplementary Materials can be found at http://www.mdpi.com/1422-0067/20/13/ 3184/s1.

Author Contributions: Conceptualization, A.G. and S.T.; data curation, A.G. and S.T.; formal analysis, A.G.; funding acquisition, A.G., S.T., and A.L.; investigation, I.K., O.K., A.M., and S.T.; methodology, A.G., I.K., O.K., A.M., P.O., A.L., and S.T.; project administration, A.G. and S.T.; resources, A.G., P.O., and P.T.; supervision, A.G. and S.T.; validation, A.G.; visualization, A.G. and I.K.; and A.G. and S.T. wrote the paper with input from all authors.

Funding: This research was funded by the Russian Foundation for Basic Research (Grant \# 18-04-00270a), the RAS Program for Molecular and Cell Biology and Post-Genomic Technologies. Works on proteins crystallization was supported by Russian Science Foundation (grant No. 17-14-01207).

Acknowledgments: We would particularly like to acknowledge Manfred S. Weiss for his assistance during the experiment at the BESSY II. We are grateful to Philippe Carpentier for the preparation of samples by his techniques.

Conflicts of Interest: The authors declare no conflict of interest.

\section{Abbreviations}

TNC TriNuclear Center

3D Three-domain

2D Two-domain

SgfSL Streptomyces griseoflavus Small Laccase

\section{References}

1. Sharma, A.; Jain, K.K.; Jain, A.; Kidwai, M.; Kuhad, R.C. Bifunctional in vivo role of laccase exploited in multiple biotechnological applications. Appl. Microbiol. Biotechnol. 2018, 102, 10327-10343. [CrossRef] [PubMed]

2. Solomon, E.I.; Sundaram, U.M.; Machonkin, T.E. Multicopper Oxidases and Oxygenases. Chem. Rev. 1996, 96, 2563-2606. [CrossRef] [PubMed]

3. Bento, I.; Martins, L.O.; Gato Lopes, G.; Arménia Carrondo, M.; Lindley, P.F. Dioxygen reduction by multi-copper oxidases; a structural perspective. Dalt. Trans. 2005, 4, 3507. [CrossRef] [PubMed]

4. Hakulinen, N.; Kiiskinen, L.-L.; Kruus, K.; Saloheimo, M.; Paananen, A.; Koivula, A.; Rouvinen, J. Crystal structure of a laccase from Melanocarpus albomyces with an intact trinuclear copper site. Nat. Struct. Biol. 2002, 9, 601-605. [CrossRef] [PubMed]

5. Skálová, T.; Dohnálek, J.; Østergaard, L.H.; Østergaard, P.R.; Kolenko, P.; Dušková, J.; Štěpánková, A.; Hašek, J. The Structure of the Small Laccase from Streptomyces coelicolor Reveals a Link between Laccases and Nitrite Reductases. J. Mol. Biol. 2009, 385, 1165-1178. [CrossRef] [PubMed]

6. Gupta, V.; Balda, S.; Gupta, N.; Capalash, N.; Sharma, P. Functional substitution of domain 3 (T1 copper center) of a novel laccase with $\mathrm{Cu}$ ions. Int. J. Biol. Macromol. 2019, 123, 1052-1061. [CrossRef]

7. Solomon, E.I.; Chen, P.; Metz, M.; Lee, S.-K.; Palmer, A.E. Oxygen Binding, Activation, and Reduction to Water by Copper Proteins. Angew. Chemie Int. Ed. 2001, 40, 4570-4590. [CrossRef]

8. Trubitsina, L.I.; Tishchenko, S.V.; Gabdulkhakov, A.G.; Lisov, A.V.; Zakharova, M.V.; Leontievsky, A.A. Structural and functional characterization of two-domain laccase from Streptomyces viridochromogenes. Biochimie 2015, 112, 151-159. [CrossRef]

9. Tishchenko, S.; Gabdulkhakov, A.; Trubitsina, L.; Lisov, A.; Zakharova, M.; Leontievsky, A. Crystallization and X-ray diffraction studies of a two-domain laccase from Streptomyces griseoflavus. Acta Crystallogr. Sect.F Struct. Biol. Commun. 2015, 71, 1200-1204. [CrossRef] 
10. Gabdulkhakov, A.G.; Kostareva, O.S.; Kolyadenko, I.A.; Mikhaylina, A.O.; Trubitsina, L.I.; Tishchenko, S.V. Incorporation of Copper Ions into T2/T3 Centers of Two-Domain Laccases. Mol. Biol. 2018, 52, $23-29$. [CrossRef]

11. Gupta, A.; Nederlof, I.; Sottini, S.; Tepper, A.W.J.W.; Groenen, E.J.J.; Thomassen, E.A.J.; Canters, G.W. Involvement of Tyr108 in the enzyme mechanism of the small laccase from Streptomyces coelicolor. J. Am. Chem. Soc. 2012, 134, 18213-18216. [CrossRef] [PubMed]

12. Jones, S.M.; Solomon, E.I. Electron Transfer and Reaction Mechanism of Laccases. Cell Mol. Life Sci. 2015, 72, 869-883. [CrossRef] [PubMed]

13. Komori, H.; Kataoka, K.; Tanaka, S.; Matsuda, N.; Higuchi, Y.; Sakurai, T. Exogenous acetate ion reaches the type II copper centre in CueO through the water-excretion channel and potentially affects the enzymatic activity. Acta Crystallogr. Sect.F Struct. Biol. Commun. 2016, 72, 558-563. [CrossRef] [PubMed]

14. Polyakov, K.M.; Gavryushov, S.; Ivanova, S.; Fedorova, T.V.; Glazunova, O.A.; Popov, A.N.; Koroleva, O.V. Structural study of the X-ray-induced enzymatic reduction of molecular oxygen to water by Steccherinum murashkinskyi laccase: Insights into the reaction mechanism. Acta Crystallogr. Sect. D Struct. Biol. 2017, 73, 388-401. [CrossRef] [PubMed]

15. Brunori, M.; Cutruzzolà, F.; Savino, C.; Travaglini-Allocatelli, C.; Vallone, B.; Gibson, Q.H. Structural dynamics of ligand diffusion in the protein matrix: A study on a new myoglobin mutant $Y(B 10) Q(E 7) R(E 10)$. Biophys. J. 1999, 76, 1259-1269. [CrossRef]

16. Luna, V.M.; Chen, Y.; Fee, J.A.; Stout, C.D. Crystallographic studies of Xe and Kr binding within the large internal cavity of cytochrome ba3 from Thermus thermophilus: Structural analysis and role of oxygen transport channels in the heme-Cu oxidases. Biochemistry 2008, 47, 4657-4665. [CrossRef] [PubMed]

17. Prangé, T.; Schiltz, M.; Pernot, L.; Colloc'h, N.; Longhi, S.; Bourguet, W.; Fourme, R. Exploring hydrophobic sites in proteins with xenon or krypton. Proteins Struct. Funct. Genet. 1998, 30, 61-73. [CrossRef]

18. Gabdulkhakov, A.; Guskov, A.; Broser, M.; Kern, J.; Müh, F.; Saenger, W.; Zouni, A. Probing the Accessibility of the Mn4Ca Cluster in Photosystem II: Channels Calculation, Noble Gas Derivatization, and Cocrystallization with DMSO. Structure 2009, 17, 1223-1234. [CrossRef]

19. Lafumat, B.; Mueller-Dieckmann, C.; Leonard, G.; Colloc’H, N.; Prangé, T.; Giraud, T.; Dobias, F.; Royant, A.; Van Der Linden, P.; Carpentier, P. Gas-sensitive biological crystals processed in pressurized oxygen and krypton atmospheres: Deciphering gas channels in proteins using a novel "soak-and-freeze" methodology. J. Appl. Crystallogr. 2016, 49, 1478-1487. [CrossRef]

20. Pavelka, A.; Sebestova, E.; Kozlikova, B.; Brezovsky, J.; Sochor, J.; Damborsky, J. CAVER: Algorithms for Analyzing Dynamics of Tunnels in Macromolecules. IEEE/ACM Trans. Comput. Biol. Bioinforma. 2016, 13, 505-517. [CrossRef]

21. Vaguine, A.A.; Richelle, J.; Wodak, S.J. SFCHECK: A unified set of procedures for evaluating the quality of macromolecular structure-factor data and their agreement with the atomic model. Acta Crystallogr. Sect. D Biol. Crystallogr. 1999, 55, 191-205. [CrossRef] [PubMed]

22. Dubé, E.; Shareck, F.; Hurtubise, Y.; Daneault, C.; Beauregard, M. Homologous cloning, expression, and characterisation of a laccase from Streptomyces coelicolor and enzymatic decolourisation of an indigo dye. Appl. Microbiol. Biotechnol. 2008, 79, 597-603. [CrossRef] [PubMed]

23. Johannes, C.; Majcherczyk, A. Laccase activity tests and laccase inhibitors. J. Biotechnol. 2000, 78, $193-199$. [CrossRef]

24. De la Mora, E.; Lovett, J.E.; Blanford, C.F.; Garman, E.F.; Valderrama, B.; Rudino-Pinera, E. Structural changes caused by radiation-induced reduction and radiolysis: The effect of $X$-ray absorbed dose in a fungal multicopper oxidase. Acta Crystallogr. Sect. D Biol. Crystallogr. 2012, 68, 564-577. [CrossRef] [PubMed]

25. Rulísek, L.; Solomon, E.I.; Ryde, U. A combined quantum and molecular mechanical study of the $\mathrm{O}_{2}$ reductive cleavage in the catalytic cycle of multicopper oxidases. Inorg. Chem. 2005, 44,5612-5628. [CrossRef] [PubMed]

26. Serrano-Posada, H.; Centeno-Leija, S.; Rojas-Trejo, S.P.; Rodríguez-Almazán, C.; Stojanoff, V.; Rudiño-Piñera, E. $X$-ray-induced catalytic active-site reduction of a multicopper oxidase: Structural insights into the proton-relay mechanism and $\mathrm{O}_{2}$-reduction states. Acta Crystallogr. Sect. D Biol. Crystallogr. 2015, 71, 2396-2411. [CrossRef] [PubMed]

27. Augustine, A.J.; Kjaergaard, C.; Qayyum, M.; Ziegler, L.; Kosman, D.J.; Hodgson, K.O.; Hedman, B.; Solomon, E.I. Systematic perturbation of the trinuclear copper cluster in the multicopper oxidases: The role 
of active site asymmetry in its reduction of $\mathrm{O}_{2}$ to $\mathrm{H}_{2}$ O. J. Am. Chem. Soc. 2010, 132, 6057-6067. [CrossRef] [PubMed]

28. Wariishi, H.; Valli, K.; Gold, M.H. Manganese(II) oxidation by manganese peroxidase from the basidiomycete Phanerochaete chrysosporium. Kinetic mechanism and role of chelators. J. Biol. Chem. 1992, 267, 23688-23695. [PubMed]

29. Heinfling, A.; Martínez, M.J.; Martínez, A.T.; Bergbauer, M.; Szewzyk, U. Purification and characterization of peroxidases from the dye-decolorizing fungus Bjerkandera adusta. FEMS Microbiol. Lett. 1998, 165, 43-50. [CrossRef] [PubMed]

30. Mueller, U.; Förster, R.; Hellmig, M.; Huschmann, F.U.; Kastner, A.; Malecki, P.; Pühringer, S.; Röwer, M.; Sparta, K.; Steffien, M.; et al. The macromolecular crystallography beamlines at BESSY II of the Helmholtz-Zentrum Berlin: Current status and perspectives. Eur. Phys. J. Plus 2015, 130, 141. [CrossRef]

31. Kraft, P.; Bergamaschi, A.; Broennimann, C.; Dinapoli, R.; Eikenberry, E.F.; Henrich, B.; Johnson, I.; Mozzanica, A.; Schlepütz, C.M.; Willmott, P.R.; et al. Performance of single-photon-counting PILATUS detector modules. J. Synchrotron Radiat. 2009, 16, 368-375. [CrossRef] [PubMed]

32. Kabsch, W. XDS. Acta Crystallogr. Sect. D Biol. Crystallogr. 2010, 66, 125-132. [CrossRef] [PubMed]

33. McCoy, A.J.; Grosse-Kunstleve, R.W.; Adams, P.D.; Winn, M.D.; Storoni, L.C.; Read, R.J. Phaser crystallographic software. J. Appl. Crystallogr. 2007, 40, 658-674. [CrossRef] [PubMed]

34. Murshudov, G.N.; Skubák, P.; Lebedev, A.A.; Pannu, N.S.; Steiner, R.A.; Nicholls, R.A.; Winn, M.D.; Long, F.; Vagin, A.A. REFMAC5 for the refinement of macromolecular crystal structures. Acta Crystallogr. Sect. D Biol. Crystallogr. 2011, 67, 355-367. [CrossRef] [PubMed]

35. Emsley, P.; Lohkamp, B.; Scott, W.G.; Cowtan, K. Features and development of Coot. Acta Crystallogr. Sect. D Biol. Crystallogr. 2010, 66, 486-501. [CrossRef]

36. Afonine, P.V.; Grosse-Kunstleve, R.W.; Echols, N.; Headd, J.J.; Moriarty, N.W.; Mustyakimov, M.; Terwilliger, T.C.; Urzhumtsev, A.; Zwart, P.H.; Adams, P.D. Towards automated crystallographic structure refinement with phenix.refine. Acta Crystallogr. Sect. D Biol. Crystallogr. 2012, 68, 352-367. [CrossRef]

37. DeLano, W.L. The PyMOL Molecular Graphics System. Available online: http://www.pymol.org/ (accessed on 25 November 2018).

(C) 2019 by the authors. Licensee MDPI, Basel, Switzerland. This article is an open access article distributed under the terms and conditions of the Creative Commons Attribution (CC BY) license (http://creativecommons.org/licenses/by/4.0/). 